\title{
Review of policies for injuries to research participants in India
}

\author{
U M Thatte, R Kulkarni-Munshi, S A Kalekar
}

Deparment of Clinical Pharmacology, TN Medical College and BYL Nair Charitable Hospital, Mumbai, India

Correspondence to: Dr R Kulkarni-Munshi, Deparment of Clinical Pharmacology, TN Medical College and BYL Nair Charitable Hospital, Mumbai Central,

Mumbai 400 008, India: clinpharm@vsnl.net

Received 6 March 2008 Revised 7 August 2008 Accepted 28 August 2008
ABSTRACT

Background: As there is little Indian data about severity, frequency and types of research related injuries, costs involved and policies regarding compensation, this study was conducted to review the present Indian scenario.

Methods: The study was carried out in three parts; a questionnaire-based survey, in-depth interviews, and a review of informed consent and insurance documents of projects submitted to three ethics committees.

Results: $47 \%$ of investigators were either unaware of, or had not understood, the legal requirements and depended on sponsors to manage these issues, whereas $74 \%$ of ethics committee members were aware of the requirements. Although $40 \%$ of investigators, $30 \%$ of ethics committee members and all sponsors had policies to manage compensation issues, these were mainly to provide immediate free medical care or reimbursement of expenses incurred for the acute management of an adverse event. Compensation for loss of time/wages, death, physical disability or long term incapacitation was not included. A review of informed consent and insurance documents showed that compensation issues were inadequately discussed, with only insurance certificates submitted to ethics committees.

Conclusion: In India, there are no uniform policies and investigators are largely unaware of their responsibilities. Therefore, there is an urgent need to draft national guidelines regarding compensation for research injuries of research participants and highlight the responsibilities of each stakeholder. Potential research injuries should be categorised based on risk assessment, severity and seriousness of the injury. Further, it would be necessary to have arbitration committees to determine the extent of compensation. Training and awareness workshops for those involved in clinical research, including research participants, is also needed.

Participation in clinical trials has both benefits and risks. Possible benefits include receiving a new treatment before it is widely available and providing useful information in relation to the safety and effectiveness of a potential new treatment, while possible risks may include occurrence of direct/ indirect physical, psychological, social and economic harms. What is more relevant is that it is not entirely possible to predict, and therefore minimise, all risks before the trial begins, as is illustrated by the completely unpredictable adverse reactions that occurred in the clinical trial of the humanised monoclonal antibody TGN1412 in which six healthy volunteers nearly died following administration of the test molecule. ${ }^{1}$

Recognising that risks are inherent to participating in a clinical trial, all current guidelines and regulations of clinical trials have attempted to define roles and responsibilities of various stakeholders in clinical trials to balance risks with the potential benefits.

An important issue that emerges in risk management in clinical trials, but has only been addressed variably ${ }^{2}$ and fleetingly, is that of compensation of research participants for injury caused while participating in the trial. One end of the spectrum is that of the USA ${ }^{3}$ where it is not binding on either sponsors or institutions to give free medical care or any other type of compensation. On the other hand European countries mandate the provision of clinical-trials insurance, through which subjects are often covered regardless of fault. ${ }^{24}$

In a country like India the issue of patient compensation is somewhat magnified because of the inherent challenges of clinical trials, for example, the concept of health insurance is not widely accepted and most trial participants are uninsured, the multitude of languages makes informed consent difficult and more importantly, therapeutic misconception is a reality.

The Indian law for clinical trials, that is, amended Schedule Y of 2005, ${ }^{5}$ Indian good clinical practice (GCP) Guidelines for Clinical Trials ${ }^{6}$ (in clause 2.4.7) and the Indian Council of Medical Research (ICMR) Ethical guidelines for biomedical research on human participants, $2000^{7}$ (section V in General ethical issues) and $2006^{8}$ (in chapters III and IV) have specified the need for provision of compensation of participants for research related injuries. There is however, little systematic information about these issues in India. This descriptive study was hence conducted to assess knowledge related to as well as to review policies among various stakeholders on compensation of research participants for clinical trial related injury in India.

\section{METHODS}

The study was carried out in three parts.

\section{Part I}

This was a questionnaire-based survey of various stakeholders involved in clinical research viz sponsors, contract research organisations, ethics committees (ECs) and investigators engaged in research. A semi-structured questionnaire was drafted that covered the main issues regarding compensation with respect to research related injuries viz awareness of present guidelines and/ or policies related to compensation for trial related injuries, implementation of the same in case of research related injuries and management of compensation claims arising out such injuries. Suggestions regarding the same were also requested, especially opinions on the role of each 
stakeholder. These questionnaires were mailed to the stakeholders with a request to complete and return. As there is no published data available on similar studies based on which the sample size could be determined, purposive sampling was done with a minimum of 25 representatives per stakeholder group so that both large and small players were included.

\section{Part II}

Based on the response received, we conducted in-depth interviews with select stakeholders to identify reasons/solutions to this issue.

\section{Part III}

In order to assess implementation of the various Indian guidelines, we reviewed informed consent documents (ICDs) of various projects submitted to one independent and two institutional ECs by random sampling. We obtained administrative approval for accessing the documents from the concerned authorities and complete confidentiality was maintained. The ICDs were studied only for relevant data without reference to the type of study, title of study or any other unrelated issue. We also reviewed the insurance documents submitted with these projects to assess the types of packages planned for managing research related injuries.

\section{RESULTS}

\section{Part I}

In an attempt to get at least 25 completed responses per stakeholder, we sent out 140 questionnaires to investigators, 96 to EC members and 37 to sponsors. The response rate ranged between 21\% (30/140) for investigators, 24\% (23/96) for EC members and $73 \%$ (27/37) for sponsors. Two sponsors refrained from replying as their internal policy did not "allow" them to share this information. The geographical distribution of the responses from various stakeholders is summarised in table 1 and illustrates a wide coverage.

Although 16 of 30 (53\%) investigators said they were aware of the requirements in the Indian laws and guidelines regarding provision of clinical-trials insurance and/or compensation for injuries during a clinical trial, only two actually mentioned that the ICMR guidelines formed their referral document. Comparatively more EC members (17 of 23 (74\%) were aware of the guidelines/laws applicable. Of these, four said that they complied with the ICMR guidelines, two with Schedule Y while two followed ABPI guidelines for compensation. Among

Table 1 Geographical distribution of the responses received to the questionnaire

\begin{tabular}{lccc}
\hline City & $\begin{array}{l}\text { Investigator } \\
\mathbf{1 4 0}(\mathbf{2 1 \% )}\end{array}$ & $\begin{array}{l}\text { EC members } \\
\mathbf{2 3 / 9 6}(\mathbf{2 4 \% )})\end{array}$ & $\begin{array}{l}\text { Sponsor/CRO } \\
\mathbf{2 7 / 3 7}(\mathbf{7 3} \%)\end{array}$ \\
\hline Bangalore & 2 & 2 & 2 \\
Delhi & 2 & 1 & - \\
Goa & 3 & - & - \\
Mumbai & 11 & 16 & 23 \\
Chennai & 2 & 1 & - \\
Ahmedabad & 1 & 1 & 1 \\
Hyderabad & 2 & - & 1 \\
Karnataka & 1 & - & - \\
Kolkata & 2 & - & - \\
Jaipur & 2 & - & - \\
Punjab & 2 & 1 & - \\
Kochi & - & 1 & - \\
\hline
\end{tabular}

CRO, contract research organisation; EC, ethics committee sponsors, 24 (89\%) indicated their awareness of the guidelines regarding compensation of which five said that they were compliant with the Indian GCP guidelines, two with Schedule Y while three complied with the ICMR guidelines.

Most of the stakeholders accepted that although there is no formal grievance redressal or arbitration committee in their organisations, as recommended by the ICMR guidelines, ${ }^{8}$ the chairperson or secretary of the EC overseeing the study and/or the principal investigator were usually considered the responsible parties, if such a situation arose. Sponsors generally had inhouse legal departments to handle compensation related issues.

Only 12 of the 30 (40\%) investigators and seven of the 23 (30\%) EC members said that their institutions had policies for the management of compensation issues in case of research related injuries while all the sponsors replied in the affirmative. However, an important point to note is that the policy was to either provide immediate free medical care or reimbursement of medical expenses incurred for the acute management of an adverse event. Legal advice regarding the same was sought by 11 $(37 \%)$ investigators, six (26\%) EC members and 25 of the 27 (93\%) sponsors prior to settling compensation claims. Only six investigators, however, said that they insisted on provisions in the trial budget for research related injury claims, (generally about $5-10 \%$ of the total budget). Four investigators and four EC members respectively said that their local ECs expected a deposit in advance from the sponsor for the management of research injuries. Twenty (74\%) sponsors said that they make provisions (5-10\% of the total trial budget) in their overall clinical trial budget, and as recommended in Schedule Y, also provided insurance cover for participants. The amount kept aside for trial related injuries varied depending on the risks of the trial, study indication, investigational product and the seriousness of the disease condition.

On the issue of research subjects being compensated for loss of time/wages in case of an injury, only six (20\%) investigators and four (17\%) EC members said that they insisted that subjects be provided compensation as they felt this to be appropriate. Thirteen (48\%) sponsors said that they provided compensation but only in certain situations viz if the same is mentioned in the study protocol, ICD or clinical trial agreement, based on the investigator's recommendations and the degree of severity of the injury.

In case of death of a research participant during a trial, sponsors said medical expenses prior to death were immediately reimbursed, although there was no policy for compensation for loss of life. Importantly, both EC members and investigators also declared an absence of any policy/guidelines on how to handle this issue-and interestingly all replied that they "had never faced such an issue".

Both investigators and EC members said that they had not faced any instance of medical negligence, fraud or protocol deviations, leading to injury to participants, till date. Two sponsors replied that management of such issues was usually done as per the clinical trial agreement between sponsor, investigator and institution and the insurance and indemnity policies as applicable. One sponsor mentioned that although the sponsor is not legally obligated to pay in cases of proven wilful medical negligence or fraud on the part of the investigator, the study subject safety is paramount and hence medical care expenses are generally taken care of. However, source documentation, protocol compliance, standard of medical care provided to the patient during the trial and the conditions under which the patient suffered the injury are looked at in 
detail by the sponsor. In doubtful cases, these issues are compensated as per court verdicts.

In case of protocol deviations, one opinion (EC member) was that if the deviation was due to either the patient's actions (not coming on scheduled date of visit), medical condition (abnormal investigations reports) or a medical decision (in the best interest of the patient), compensation need not be made to the participant. However, 26 (96\%) sponsors said injuries occurring following protocol deviations (done with prior intimation and approval of the sponsor and substantiated by reasonable justification), were financially compensated for medical management. Compensation was also provided as very often it was not possible to differentiate protocol deviation related injuries from other adverse events.

All the stakeholders agreed that the financial responsibility of the trial related injury was that of the sponsor. This is generally documented in the clinical trial agreement and there is provision of an insurance cover with an additional indemnity cover for investigators and the study team. However, 20 (67\%) investigators and 11 (48\%) EC members said that the research participant or relatives had to first pay to manage the injury. They were reimbursed after providing proof of such a payment.

Regarding the type of contracts entered into with insurance agencies with respect to research related injury claims, 25 (83\%) investigators and 19 (83\%) EC members were unaware of the details of the contracts. We found from sponsors (who were more aware about the contracts) that the type of insurance was either product liability or clinical trial specific annual contracts with insurance agencies, which were renewed every year. In the case of multinational studies, sponsors generally preferred a global insurance cover. In addition, they also made provisions for a professional indemnity insurance policy for the investigators

The questionnaire responses received on research injury related issues are summarised in table 2 .

\section{Part II}

Based on the responses of the questionnaire based survey received, in-depth interviews were conducted with key stakeholders. Three investigators, six EC members (including three lawyers) and five sponsors were interviewed individually to assess their understanding of the issue of compensation for research related injury, as well as to determine if any recommendations could be made towards the development of guidelines for compensation.

Many of the issues elicited in Part I were reiterated during interviews. The major point that was emphasised by all interviewees was the lack of awareness among investigators and EC members regarding this issue of compensation. Investigators (and through them EC members) relied entirely on sponsors to make arrangements for payment and never went into the details.

Although EC members said that the committees they served on insisted on submission of a compensation plan for research participants, due to paucity of time and lack of competence or expertise, very few members actually went through the documents for appropriateness. Additionally, many felt an urgent need for a dedicated legal person in every EC to undertake the responsibility of overseeing all legal issues related to clinical trials. EC members also mentioned the importance of the ICD to make the patient aware of his rights during the trial participation in terms of compensation for research related injuries.
An important issue that arose during interviews was of the varying compensation amounts in international trials depending on where the trial was being performed. For example, Indian patients were insured for lesser amounts per event as compared to patients in the USA for research related injury. Sponsors justified this on the basis of variable "standard of living" in different countries.

Interestingly, sponsors suggested that ECs should play a more active role in ensuring that adverse events are managed efficiently by investigators both medically and financially, that is, confirmation of payment or reimbursement of medical expenses and that there should be quality audits of investigators and study sites for compliance with such policies.

The regulatory aspects of the issue were discussed with the Drugs Controller General of India (DCGI). He noted that although it was clear that the financial responsibility for managing research related injury lay with the sponsor this needed to be brought under legislation. The DCGI also suggested that injuries should be categorised based on the severity, seriousness and the compensation determined accordingly by a third party (such as an EC).

As insurance is an important mechanism to cover the expenses of research related injuries, discussions were also held with two insurance companies providing insurance for clinical trials and one agent who acted as a go-between among sponsors and insurance companies. Incomplete knowledge of the needs and guidelines relating to clinical trials was an important observation during these interviews. Sponsors generally influenced the framing of insurance policies and international formats were often used to draft insurance policies.

Another often repeated point was the need to prove "causality" for injury (as being due to research procedure/ medication) before compensation was considered or given. Further, there were concerns about the fact that patients had to pay first (and this could be debilitating in a country like India) and then only after submitting proof of expense would the patient be compensated.

A common refrain from the interviews was the need for nationally relevant guidelines on compensation issues, especially on the extent.

\section{Part III}

In order to assess whether attempts were made to make patients aware of compensation issues, we studied 119 ICDs of different clinical trials from the years 2000-2007. These were selected randomly from projects submitted to two institutional ethics committees and one independent ethics committee. Appropriate permissions were obtained and strict confidentiality was maintained. Of these, 100 were clinical trials sponsored by pharmaceutical companies while 19 were intramural studies. Only ICDs from EC approved studies were reviewed.

Interestingly, in the early years after the publication of the ICMR guidelines $(2000)^{7}$ and the Indian GCP guidelines (December 2001) ${ }^{6}$ (ie, between 2000-2002) the ICDs did not provide details of compensation, even though both national guidelines clearly stated that the protocol and ICD must have this information. Only from 2003 did we find ICDs mentioning this issue as a separate point in the document. Interestingly, ICDs of intramural research projects and trials related to herbal medicines tended not to have any compensation mentioned. In 2003, $50 \%$ (4 of 8) of the ICDs mentioned the issue of compensation, and this increased to $62 \%$ (16 of 26 ), $71 \%$ (12 of 
Table 2 Responses received to the questionnaire survey on research injury related issues

\begin{tabular}{|c|c|c|c|}
\hline \multirow[b]{2}{*}{ Question } & \multicolumn{3}{|c|}{$\begin{array}{l}\text { No of (\%) Stakeholders with positive } \\
\text { replies }\end{array}$} \\
\hline & $\begin{array}{l}\text { Investigator } \\
(30 / 140)\end{array}$ & $\begin{array}{l}\text { EC } \\
\text { member } \\
(23 / 96)\end{array}$ & $\begin{array}{l}\text { Sponsor// } \\
\text { CRO (27/ } \\
\text { 37) }\end{array}$ \\
\hline $\begin{array}{l}\text { General awareness of the requirements as } \\
\text { per Indian laws and guidelines regarding } \\
\text { provision of clinical-trials insurance and/or } \\
\text { compensation for injuries during clinical trial }\end{array}$ & $16(53)$ & $17(74)$ & $24(89)$ \\
\hline $\begin{array}{l}\text { Whether the institution/organisation has a } \\
\text { policy for managing compensation issues }\end{array}$ & $12(40)$ & $7(30)$ & 27 (100) \\
\hline $\begin{array}{l}\text { Whether the institution/organisation has } \\
\text { mechanisms for grievance redressal of a } \\
\text { research subject? }\end{array}$ & $11(37)$ & $14(61)$ & $14(52)$ \\
\hline $\begin{array}{l}\text { Number of instances where compensation } \\
\text { been provided? }\end{array}$ & $1(3)$ & $2(9)$ & $4(15)$ \\
\hline $\begin{array}{l}\text { Do you agree that the subject should be } \\
\text { compensated for the loss of time/wages due } \\
\text { to injury? }\end{array}$ & $6(20)$ & $4(17)$ & $13(48)$ \\
\hline $\begin{array}{l}\text { Does your institution make provisions in the } \\
\text { trial budget for research related injury claims? }\end{array}$ & $6(20)$ & - & $20(74)$ \\
\hline $\begin{array}{l}\text { Does your ethics committee expect a deposit } \\
\text { in advance from the sponsor to manage } \\
\text { research related injuries prior to granting } \\
\text { permission for a clinical trial? }\end{array}$ & $4(13)$ & $4(17)$ & $2(8)$ \\
\hline $\begin{array}{l}\text { Does the sponsor have to bear the entire } \\
\text { financial responsibility of the compensation } \\
\text { claim? }\end{array}$ & $30(100)$ & $3(13)$ & $27(100)$ \\
\hline $\begin{array}{l}\text { Does your organisation enter into a contract } \\
\text { with an insurance agency regarding the } \\
\text { finances for research related injury claims? }\end{array}$ & $5(17)$ & $4(17)$ & $20(74)$ \\
\hline $\begin{array}{l}\text { Is it required for the subject to pay first and } \\
\text { then be compensated after providing proof of } \\
\text { such a payment? }\end{array}$ & $20(67)$ & $11(48)$ & $11(41)$ \\
\hline $\begin{array}{l}\text { Is legal advice sought prior to accepting } \\
\text { compensation claims? }\end{array}$ & $11(37)$ & $6(26)$ & $25(93)$ \\
\hline
\end{tabular}

CRO, contract research organisation; EC, ethics committee

17), $91 \%$ (40 of 44 ICDs) and $83 \%$ (10 of 12 ICDs) over the years from 2004 to 2007 respectively.

In the ICDs that mentioned compensation for trial related injury, it was noted that most ICDs mentioned that "medical care" would be provided for management of trial related adverse events and that the financial burden would be borne by the sponsors. Only in two cases (in 2005) was it actually mentioned that the sponsor would provide monetary compensation of medical expenses for management of research related injury.

As was observed in Parts I and II, we found that one in 26 ICDs (4\%) in 2004, none in 2003 and 2005, seven of 44 ICDs $(16 \%)$ in 2006 and four of 12 ICDs (33\%) in 2007 stated that compensation would be given only after it was confirmed that the injury was due to the trial drug or procedure and if the medical care of the adverse event was not covered by the subject's own or hospital's insurance policy.

As summarised in table 3, the ICDs either did not refer to compensation for lost wages, disability, discomfort or death, or did not provide for the same.

A huge variation was noted in the language and also the type of compensation offered for managing research related injury. Some companies provided an insurance cover to patients, some offered medical care only if not already provided by patient's medical insurance, while others mentioned ambiguous statements like "compensation for injury will be in accordance with national and international terms and/or guidelines". One ICD (2004) stated "that compensation will be provided in accordance with Indian law" (which was not amended at that time to include this issue) while a newer one (2007) mentioned that "payment of medical expenses could be obtained from the study director".

Although all Indian guidelines and Schedule Y mention that insurance can be one way of covering medical expenses of adverse events or compensating for disability, we found that very few ICDs said this (about 8\% in 2004 increasing slowly to about $50 \%$ in 2007; see table 3).

Insurance documents that were available with the projects were also reviewed with respect to the type of policy issued, duration of the policy, terms and conditions, and limits of insurance provided to research subjects. Most of the documents submitted to ECs were insurance certificates and only three of the $18(16.67 \%)$ documents reviewed had complete details of the policies enclosed. The type of insurance provided in five $(28 \%)$ of the cases was a "product liability insurance". The duration of most of the policies was one year or more depending on the study duration. Although the limits of insurance (overall aggregate and per occurrence limit) were mentioned in all the documents, only four certificates (22\%) were accompanied by the terms and conditions of the policy. The information obtained on review of the insurance documents are summarised in table 4.

\section{DISCUSSION}

When a subject is injured as a result of participation in a research study it is called a "research related injury". Such injuries may range from relatively minor harms (such as bruises due to a study procedure or vomiting due to a new drug), to major injuries (such as organ damage or temporary physical disability), to catastrophic injuries (such as permanent disability or death). Injuries can be physical, psychological/emotional, social or economic and may require only acute or emergency care, or long term medical care.

Although Indian guidelines and law ${ }^{5-8}$ have specified the need for provision of compensation of participants for research related injuries, there is little systematic information about these issues in India. Our study documents for the first time the current Indian situation with respect to these issues.

Using a questionnaire based survey, in-depth interviews and a study of ICDs, we found that essentially in India only sponsors have clear-cut policies regarding the management and compensation of patients in case of research related injuries. Awareness about current Indian guidelines related to this issue was inadequate among stakeholders, particularly investigators. It was also evident from our study that compensation was limited to the acute management of the adverse events occurring during a trial. The issue of compensation for lost wages during the adverse event or for death, permanent disability or long-term incapacitation was not addressed by any of the stakeholders, including sponsors even though this is clearly mentioned in the ICMR guidelines. Further, and perhaps somewhat disturbing, is that largely the patient had to pay for the adverse event management and he/she would be compensated later. There is very little experience in the case of fraud or negligence leading to adverse events and all stakeholders appeared unsure of how to deal with it, although sponsors in general appeared to be keen on accepting responsibility.

Although primarily responsible to review and approve, it was disconcerting to note that $83 \%$ of EC members were unaware of the details of insurance contracts. There is a large knowledge gap here that needs to be addressed.

The key issue repeatedly raised in the in-depth interviews was the general lack of awareness among investigators regarding the 
Table 3 Important points observed in the informed consent documents

\begin{tabular}{|c|c|c|c|c|c|c|c|c|}
\hline $\begin{array}{l}\text { Points covered in informed consent documents } \\
\text { (ICDs) }\end{array}$ & Analysis & & & & & & & \\
\hline Year of submission of trial to Ethics Committee & 2000 & 2001 & 2002 & 2003 & 2004 & 2005 & 2006 & 2007 \\
\hline No of ICDs reviewed & 2 & 6 & 4 & 8 & 26 & 17 & 44 & 12 \\
\hline \multicolumn{9}{|l|}{ Type of compensation that would be provided } \\
\hline c) Monetary Compensation & & - & - & - & - & $2(12 \%)$ & - & - \\
\hline Whether Expenses would be borne by the sponsor? & & $1(17 \%)$ & - & $4(50 \%)$ & $15(58 \%)$ & $5(29 \%)$ & $27(61 \%)$ & $5(42 \%)$ \\
\hline $\begin{array}{l}\text { Whether payment for lost wages/disability/ } \\
\text { discomfort would be provided in case of a trial } \\
\text { related injury? }\end{array}$ & NM & NM & NM & NM & $\begin{array}{l}\text { No-8 }(31 \%) ; \\
\text { NM-16 } \\
(69 \%)\end{array}$ & $\begin{array}{l}\text { No-5 (29\%) } \\
\text { NM-12 (71\%) }\end{array}$ & $\begin{array}{l}\text { No-15 (34\%) } \\
\text { NM-29 } \\
(66 \%)\end{array}$ & $\begin{array}{l}\text { No-5 }(42 \%) \text { NM-7 } \\
(58 \%)\end{array}$ \\
\hline \multicolumn{9}{|l|}{$\begin{array}{l}\text { Any clauses mentioned regarding when } \\
\text { compensation would be provided? }\end{array}$} \\
\hline $\begin{array}{l}\text { d) Compensation/reimbursement only of the } \\
\text { additional amount not covered by subject's } \\
\text { medical insurance? }\end{array}$ & - & - & - & & $1(4 \%)$ & - & $4(9 \%)$ & $3(25 \%)$ \\
\hline $\begin{array}{l}\text { Did the ICD mention an insurance policy that } \\
\text { covers trial related injuries? }\end{array}$ & - & - & - & - & $2(8 \%)$ & $3(18 \%)$ & $6(14 \%)$ & $6(50 \%)$ \\
\hline
\end{tabular}

NM, not mentioned

issue of compensation for research related injuries. Although EC members felt the need to review compensation plans and documents, they said this was not done during the review of projects and what was interesting was that they attributed this to a lack of both time and expertise.

The study of ICDs was extremely interesting. The evolution of the process of informed consent and the impact of the guidelines and laws in India were evident with improving standards in ICDs. However, there appears still to be some gaps and this highlights perhaps the need for regulatory inspections of clinical trials to ensure further compliance. The study of ICDs confirmed that compensation was mainly in the form of medical care of trial related adverse events and that the financial burden was borne by the sponsors. The compensation is in the form of "reimbursement" and is often related to proving "causality". This was a disturbing observation as compensating

Table 4 Information obtained from the insurance documents reviewed

\begin{tabular}{|c|c|c|c|c|}
\hline & \multicolumn{4}{|c|}{$\begin{array}{l}\text { Number of insurance documents providing } \\
\text { required information }\end{array}$} \\
\hline & 2004 & 2005 & 2006 & 2007 \\
\hline & 3 & 2 & 7 & 6 \\
\hline $\begin{array}{l}\text { Insurance documents with } \\
\text { complete policies }\end{array}$ & 1 & 1 & 0 & 1 \\
\hline \multicolumn{5}{|l|}{ Type of insurance provided } \\
\hline a) Clinical trial insurance & - & 1 & 3 & 6 \\
\hline b) Product liability insurance & 2 & 1 & 2 & - \\
\hline c) Professional indemnity & 1 & - & - & - \\
\hline \multicolumn{5}{|l|}{ Duration of the insurance policy } \\
\hline a) 1 year & 2 & 1 & 2 & 4 \\
\hline b) 1-3 years & 1 & 1 & 3 & 1 \\
\hline Term and conditions enclosed & 1 & 1 & 1 & 1 \\
\hline Limits of insurance mentioned & 3 & 2 & 5 & 5 \\
\hline
\end{tabular}

a patient for research related injury appears appropriate and ethical without having to prove that it is related to the trial drug and this principle has been embedded in most ethical guidelines, including the ICMR guidelines. ${ }^{8}$

Through the study of ICDs it was clear that there are no plans to compensate in cases of death or disability. Lack of uniformity in the language and the type of compensation offered were clearly noted in ICDs and must be changed. This issue of the use of ambiguous terms with respect to compensation for research injuries has been raised by different authors including EC members. ${ }^{9-12}$

A look at the global situation also indicates a conflict regarding the issue of compensation in case of research related injuries. In the USA, it is not mandatory by law for sponsors and institutions to provide either free medical care or compensation for research related injuries to trial participants, apart from general tort law principles that apply to everyone. ${ }^{3} 13$ A study conducted by the Department of Health and Human Services found that most research institutions do not have policies that provide free care or compensation to injured participants. Of the 129 policies at 102 academic medical centres reviewed, it was observed that no institution or sponsor offered compensation for lost wages or pain and suffering; only 21 policies "involved providing free care or treatment", and that health insurance served as the primary vehicle for compensation of such injuries. ${ }^{214}$ Another survey too found considerable variation among the compensation-for-injury policies adopted by American medical schools. Coverage for medical bills was offered by $61 \%$ of schools when there was an industry sponsor as compared with $22 \%$ when there was none. Among those schools that offered to cover medical bills in studies with no industry sponsor, $50 \%$ offered to cover only emergency care. In all, $72 \%$ of the ICDs specifically ruled out the possibility of monetary compensation. ${ }^{12}$ However, US Federal research regulations do require that researchers discuss the issue of 
compensation for injury with subjects during the informed consent process, if the research is classified as more than minimal risk. ${ }^{15}$

In contrast, many European countries mandate the provision of clinical trials insurance, through which subjects are often covered regardless of fault. The European Union Clinical Trials Directive, now transposed into National law through the Medicines for Human Use (Clinical Trials) Regulations 2004 has legally defined responsibilities on those commissioning and carrying out drugs trials as well as the responsibilities of the ECs and the Medicines and Healthcare Products Regulatory Agency. ${ }^{4}$ These include the need for those commissioning and conducting drug trials to have adequate insurance should the trial go wrong. Countries such as France, Germany and Spain, have compulsory insurance laws with variations in the specifics and minimum coverage required. ${ }^{2}$ In fact, awareness of the need for a legal framework to protect those involved in biomedical research led the French Parliament to pass a law for the Protection of Persons Undergoing Biomedical Research commonly known as the Huriet Law. This law makes the sponsor financially responsible to research participants for adverse events occurring during clinical trials through mandatory insurance coverage. ${ }^{16}$ Scandinavian countries like Sweden, Finland, Denmark and Norway favour a no-fault principle in dealing with medical injuries, relying on insurance rather than litigation. ${ }^{17-21}$

The Association of the British Pharmaceutical Industry guidelines on compensation for trial related injuries ${ }^{22}{ }^{23}$ also recommend that subjects suffering from research related injuries be compensated on a "no fault" basis. These guidelines have been modified and adopted by many other countries such as South Africa, ${ }^{24}$ Australia ${ }^{25}$ and New Zealand. ${ }^{26}$ Unfortunately, these guidelines clearly state that there is "no legal commitment" to pay compensation for research related injuries thus not adequately protecting research participants. ${ }^{27}$

There is evidently an urgent need to develop and implement clear guidelines with regard to compensation for research related injuries (both management of adverse events as well compensation in case of death, disability, long-term incapacitation or development of congenital anomalies) in consultation with all stakeholders involved in clinical research, legal counsel (in keeping with the requirements spelt out in Schedule Y, 2005 and ICMR guidelines of 2006). These guidelines need to clearly spell out the responsibilities of each stakeholder, including the role of the ethics committee while approving trials or settling claims. Issues such as compensation to be given to research subjects in case of government sponsored studies and clinical trials with herbal drugs where adverse events are not/least expected also need to be addressed. An important aspect of these guidelines would be to categorise potential injures likely to be faced during clinical trials, including risk assessment of the injury to enable assessment of extent of compensation due. Setting up of an arbitration committee, as per the ICMR Guidelines, and the operating procedures of this committee, need to be elaborated. The New Zealand's government-funded no-fault compensation system, $2005^{28}$ for the compensation of all medical (not restricted to research) injuries can be adapted by stakeholders to determine the amount of compensation to research participants injured in clinical trials.

Lastly, there is also an urgent need for training and awareness workshops for all those involved in clinical research, including research participants. A workshop with insurance companies is also required to create in them awareness regarding the needs from a patient's perspective: the participant takes the risk, but is covered by the sponsor with an insurance policy and the conditions are then approved by the ethics committees and investigator.

Acknowledgements: Financial and technical assistance: CDSCO, Ministry of Health and Family Welfare, Government of India and WHO Country Office for India A sincere thanks to all those who participated in the study in spite of their busy schedules and provided scientific inputs (their names have not been disclosed for confidentiality purposes)

Funding: Essential Drugs \& Medicine, WHO India Country office 536 A Wing, Nirman Bhavan, New Delhi 110011

Competing interests: None.

\section{REFERENCES}

1. Goodyear M. Learning from the TGN1412 trial. BMJ 2006;332:677-8

2. Steinbrook R. Compensation for injured research subjects, NEJM 2006;354:18713 .

3. National Institute of Health; Office of the Human Subject Research. OHSR information sheets/forms. http://ohsr.od.nih.gov/info/sheet6.html laccessed 29 Oct 2008).

4. Statutory Instrument 2004 No. 1031 The medicines for human use (clinical trials) regulations 2004. http://www.opsi.gov.uk/si/si2004/20041031.htm (accessed 29 0ct 2008).

5. Amended Schedule $\mathbf{Y}$ (Drugs and Cosmetics Act ( $2^{\text {nd }}$ Amendment) Rules. 20 January 2005, New Delhi. See http://www.cdsco.nic.in/html/ScheduleY\%20(Amended\%20Version-2005)\%20original.htm (accessed 29 0ct 2008).

6. Central Drugs Standard Control Organization. Good clinical practices for clinical research in India. December 2001. http://cdsco.nic.in/html/GCP.htm laccessed 29 Oct 2008).

7. Indian Council of Medical Research (ICMR). Ethical guidelines for biomedical research on human subjects. 2000. http://www.icmr.nic.in/buoct2000.htm (accessed 29 Oct 2008).

8. Indian Council of Medical Research (ICMR). Ethical Guidelines for Biomedical Research on Human Subjects. 2006. http://www.icmr.nic.in/ethical.pdf (accessed 29 Oct 2008).

9. Hochhauser M. Paying for research related injuries in the US. BMJ 2006;332:610

10. Laurence DR. Compensation for non-negligent harm in trials remains shaky. BMJ 2006;332:489-90.

11. Marwick C. Compensation for injured research subjects JAMA 1998;279:1854

12. Paasche-Orlow MK, Brancati FL. Assessment of medical school institutional review board policies regarding compensation of subjects for research-related injury. Am J Med 2005;118:175-80.

13. Resnik RB. Compensation for research-related injuries: ethical and legal issues. J Leg Med 2006;27:263-87.

14. The Lewin Group. Task order proposal no. 2: care/compensation for injuries in clinical research. Draft of the final report prepared for the Department of Health and Human Services Office of the Assistant Secretary for Planning and Evaluation. Falls Church, Va.: The Lewin Group, May 18, 2005. (Contract no. HHS 100-03-0005.)

15. United States Department of Health and Human Services Code of Federal Regulations (CFR) Part 46. Protection of human subjects. Section 116. http://www. hhs.gov/ohrp/humansubjects/guidance/45cfr46.htm (accessed 29 0ct 2008).

16. Berlin I, Gorelick DA. The French law on "protection of persons undergoing biomedical research": implications for the US. J Law Med Ethics 2003;31:434-41.

17. Gaine WJ. No-fault compensation systems. BMJ 2003 May 10;326:997-8.

18. The Medical Product Agency's provisions and guidelines on clinical trials of medicinal products for human use, Sweden. http://www.lakemedelsverket.se/Tpl/ NormalPage_2159.aspx (accessed 29 Oct 2008).

19. Regulation relating to clinical trials on medicinal products for human use (FOR 2003-09-24 nr 1202), Norway. http://www.legemiddelverket.no/upload/ 31448/FOR\%202003-09-24\%20nr\%201202\%20english.pdf (accessed 29 0ct 2008)

20. Medical Research Act, Finland. Ethical evaluation of research in Finland. http:// www.tenk.fi/ENG/Publicationsguidelines/EthicalEvaluationofResearchinFinland.pdf (accessed 29 0ct 2008)

21. Act on a Biomedical Research Ethics Committee System and the Processing of Biomedical Research Projects, Denmark. http://www.cvk.im.dk/cvk/site.aspx?p = 150 (accessed 29 Oct 2008)

22. ABPI Guidelines for Phase I studies 2007 edition. http://www.abpi.org.uk/ publications/pdfs/phase1_guidelines.pdf (accessed 29 0ct 2008).

23. ABPI guidelines for phase II/III studies. Clinical trials compensation guidelines. http:// www.abpi.org.uk/publications/pdfs/Clinical-Trial-Compensation-GLs.pdf (accessed 29 Oct 2008).

24. The Clinical Trials Committee of the South African Medicines Control Council. Appendix IV: clinical trial compensation guidelines. http://www.sahealthinfo. org/ethics/book1appen4.htm (accessed 29 Oct 2008)

25. Guidelines for Compensation for Injury resulting from participation in a company sponsored clinical trial, Australia. http://www.medicinesaustralia.com.au/pages/ images/CInical\%20Trials\%20Compensation\%20Guidelines.pdf laccessed 29 0ct 2008). 
26. Researched Medicines Industry. Guidelines on clinical trials compensation for injury resulting from participation in an industry-sponsored clinical trial. http://www. rmianz.co.nz/compensation\%20guidelines\%200808\%20final.pdf (accessed 11 Nov 2008)
27. Guest S. Compensation for subjects of medical research: the moral rights of patients and the power of research ethics committees. J Med Ethics 1997;23:181-5.

28. Bismark M, Paterson R. No-fault compensation in New Zealand: harmonizing injury compensation, provider accountability, and patient safety. Health Aff 2006;25:278-83 